\title{
Geodetic Activities in Lithuania \\ Related to Aalborg University
}

\author{
by \\ Kai Borre, Aalborg University
}

\section{The Start}

When I arrived at my office March 21, 1991 a nice gentleman was waiting for me. His name was Vytautas Tulevičius and was an associate professor at Vilnius Technical University. He was member of a delegation from that university visiting Aalborg. He left my room four hours later after inviting me to his country to tell about western technology within geodesy and neighboring disciplines.

Already from August 1991 a student from Department of Geodesy, Vilnius Technical University visited Aalborg University. The stay was supported by the Rector of our University. The name of the student is Arūnas Büga and he stayed till February 1992. It turned out that Arünas became instrumental for the coming activities.

In October 1991 I flew to Riga from where we went by car to Vilnius; we arrived in the morning. This first visit lasted for two weeks and I returned with a fairly good impression of the professional activities in Lithuania.

\section{The First Grant}

In the summer 1992 the Danish government granted eight GPS receivers and a lot of electronic equipment to the state of Lithuania. I remember clearly an afternoon in September when a large wooden box arrived from Denmark with the equipment and a Customs officer was present and we drank champagne.

We started courses at Vilnius Gediminas Technical University (VGTU) for persons interested in how GPS equipment works. Below I quote a note written on September 11, 1992 about these first GPS data:

These files are the first ones ever produced by Lithuanian operators and Lithuanian GPS receivers on Wednesday September 9, 1992. The receivers are Ashtech $\mathrm{P}$-code dual frequency receivers.

The DOP values are large due to lunch break. The epochs are collected an hour after the optimal window. GPPS gives a good performance if we in 'Run-Time Parameters' use the following choices 
After running adjustin and fillnet we get $\sigma_{0}=0.169$, and translations of 2,3 , and $3 \mathrm{~mm}$.

$L_{2}$ data alone give a good solution; this I do not understand. (Later on the answer was found in the NANU messages!)

Some additional results of computations:

UTM zone 33

$\begin{array}{ccc}\text { Point } & N[\mathrm{~m}] & E[\mathrm{~m}] \\ 0001 & 6113180.601 & 1164731.314 \\ 4024 & 6113433.485 & 1164692.217 \\ 7954 & 6113040.201 & 1164700.676 \\ 8095 & 6113064.008 & 1164882.426\end{array}$

Mapping equations

\begin{tabular}{lccrrrr}
\multicolumn{7}{c}{$\eta=0.12902130 y+0.99671838 x-464.4500$} \\
\\
scale & 1.00503434 & & & \\
point & $y$ & $x$ & $\eta$ & $\xi$ & $d \eta$ & $d \xi$ \\
4024 & 523.446 & 833.158 & 433.485 & -692.217 & -0.025 & -0.007 \\
7954 & 481.618 & 443.965 & 40.201 & -700.676 & 0.004 & 0.058 \\
8095 & 663.893 & 444.239 & 64.008 & -882.426 & 0.021 & -0.051 \\
$\sigma_{0}=0.059 \mathrm{~m}$ & & & & &
\end{tabular}

It is known that the given $(y, x)$ coordinates are not accurate. So the result is encouraging.

A group of persons planned the new fundamental network. It was measured during May 1993, mainly, and computed at my home in Denmark later that year by Eimuntas Paršeliūnas. Before Christmas 1993 we had computed new coordinates of the fundamental network.

The Danish support for the fundamental network finished at the end of that year. The entire activity was a success. The newly observed GPS network was close to being identical to the old triangulation network. The processing was done on a baseline-bybaseline manner. That was the only available method at that time.

Years later, in 2001 two Lithuanian students Darius Popovas and Kristina Radzevičiute finished their thesis "Adjustment of the Lithuanian GPS Network Using GAMIT" as part of their studies at Aalborg University. The work readjusts the Lithuanian GPS network using the GAMIT software from Massachusetts Institute of Technology. It is a powerful software which allows implementation of advanced models. The data from 1993 were reprocessed first session by session, and later combined into a final adjustment taking into account the correlations between different sessions. The results were compared with the previous ones from 1993, confer Figure 1. No difference between the preliminary and the final plane coordinates was larger that 2 centimeters and no height difference larger than 4 centimeters. The confidence ellipses for the GAMIT adjustment are shown in Figure 2. The entire report can be downloaded from gps.aau.dk/educate/Edu_projects_3rd.htm 


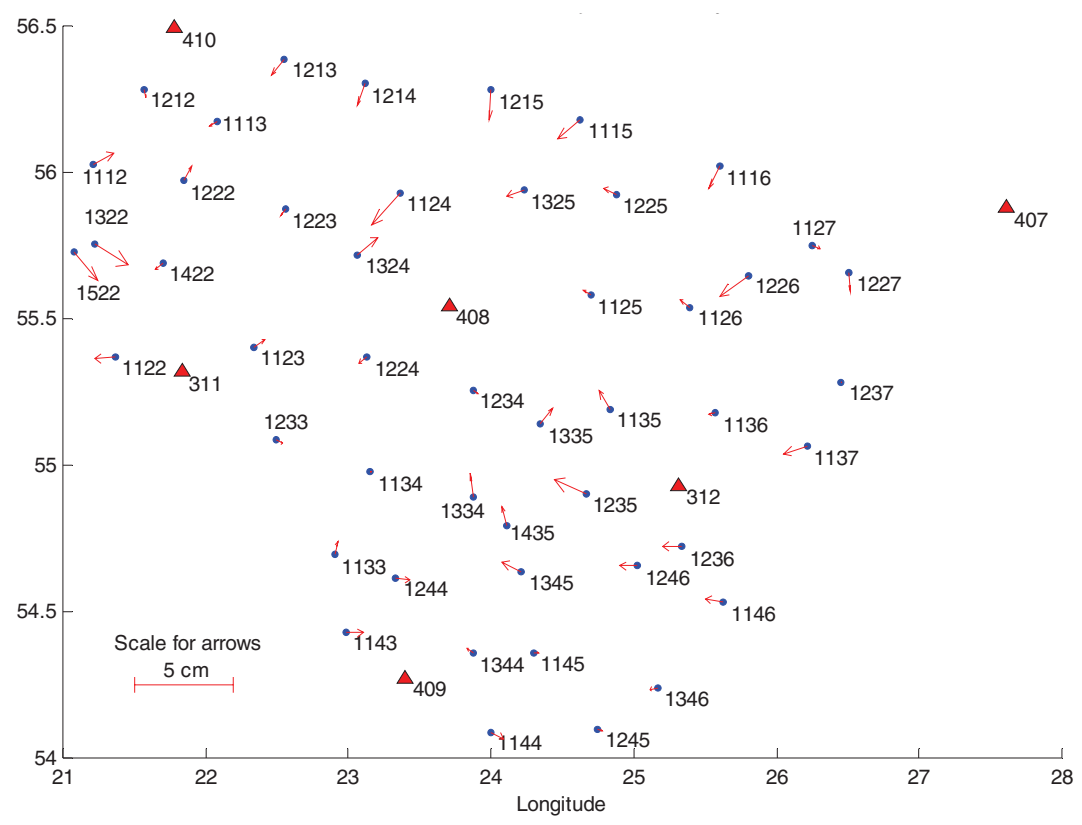

Figure 1: Differences between the plane coordinates from the 1993 adjustment and from the GAMIT adjustment. Coordinates are common at six points. From Popovas and Radzevičiutè.

A densification of the fundamental network started late 1993 and in 1995 all sites in Lithuania are less than $10 \mathrm{~km}$ from a GPS coordinated control point. This development took several decades in my country and still today the coordinates in my country are not as good as the Lithuanian ones.

\section{Further Grants}

A subsequent era (1994-1995) opened with a grant from the Council of Nordic Ministers facilitating that I regularly visited VGTU to lecture on various geodetic topics. That also made it possible for me to follow and give advice on the geodetic and cartographic developments in Lithuania.

In the years 1996-1998 the Danish Ministry for Education supported two so-called sandwich scholarships that were given to Arūnas Būga and Ričardas Kolosovskis.

\section{The Galileo Era}

In July 2004 Günter Hein, Bundeswehr Universität München and Kai Borre visited Lithuania in order to introduce the upcoming Galileo system. Lithuania is a member of the action and the aim of the visit was to investigate the possibilities for concrete cooperation and participation from Lithuanian side.

On July 21 an introduction to the political and organizational aspects of the Galileo activities was offered at the Ministry of Transportation. 


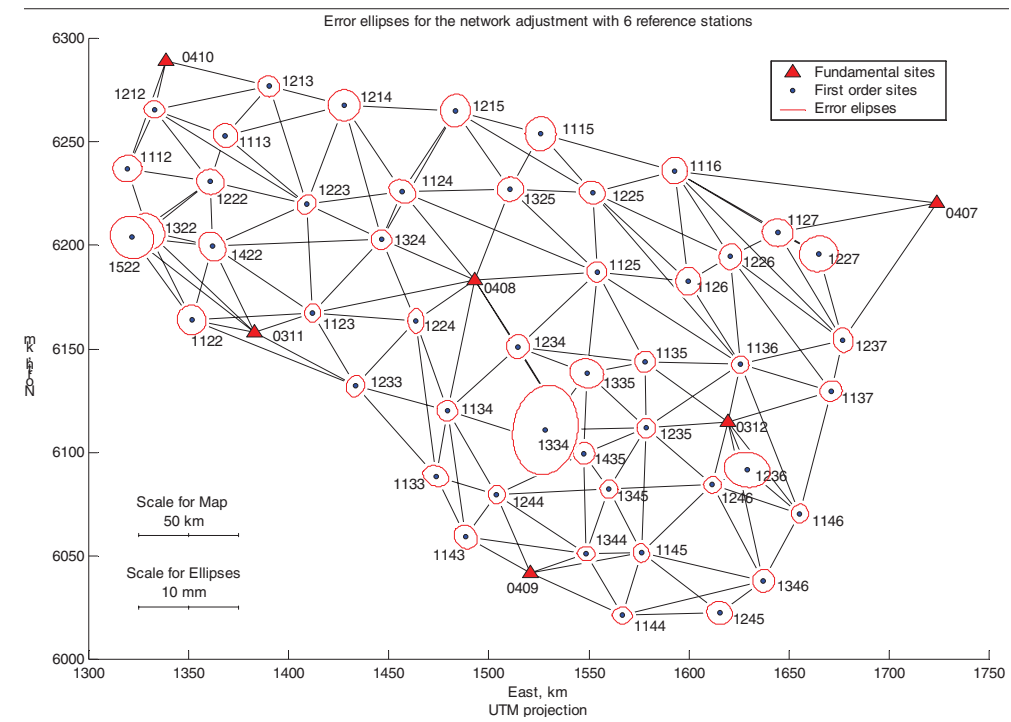

Figure 2: Confidence ellipses for the Lithuanian fundamental network with postulated coordinates at six stations. From Popovas and Radzevičiūtè.

On July 22 Günter Hein focussed on professional issues at VGTU, while Kai Borre lectured on a topic selected with great care: In recent years there has been a remarkable decline in number of students attracted by geodesy and surveying. This global trend has led to numerous reorganizations of curricula or even abolishments of former strong institutes. There is hardly any reason why this development shall not come to Lithuanian universities. In parts of Europe we note that if classical surveying institutes are not changing their curriculum to massively include satellite based navigation they are facing a closure threat. Modern students are attracted by disciplines like computer science, aeronautics, and biometrics.

\section{Lessons Learnt}

I have spent about a year in Lithuania. The stays have given me an invaluable insight which one never gains by sitting behind a writing table at Copenhagen. The success of the activities is undoubtedly connected to an intimate cooperation between the participating parties. When one task was finishing the next one was planned with due respect to all relevant wishes from both the supporting part and the receiving one.

The Lithuanian geodetic community has received help from various sources since 1991. In several cases foreign helpers wanted to promote own interests and this is not always an optimal procedure when recovering from scratch. In my opinion the geodetic community as such has managed well to handle this situation. Geodesy in Lithuania has achieved remarkable results within a short period of time and of very high quality.

The international relations are maintained through the International Symposia on Environmental Engineering. The sixth such symposium is planned for May 2005. These gatherings allow for exchange of ideas and plans for future professional activity. Attending these meetings allows me to follow students who have completed two years 
of master study at Aalborg University; this is a great comfort for the old teacher.

Along with the officially supported activities there was also time to establish commercial relationships and new business, professional and non-professional.

Following closely the Lithuanian cultural life over more than a decade has resulted in diverse contacts to musicians, painters, actors, singers, intellectuals; these contacts resulted in privately arranged concerts, paint exhibitions, and training courses of different sort in Denmark.

It is close to fourteen years since I met the first Lithuanian in my life. This meeting was the start of a new and joyful part of it. I realized that Lithuanians and Danes have same sort of humor and go along very well, although we are separated by a sea.

Of course, half a century with Soviet regime leaves traces. I found that many people were reluctant to take responsibility and expected someone else to take the lead. Reactions often were influenced by fear and not always rationality. It took me some time to figure this out.

In connections with accommodation, transportation, and shopping I got much help from all sides, even the most unexpected ones. I'm still grateful for this. In the early days minor practical problems had a tendency to become today's problem. Many persons were helpful to fetch me and bring me, to bring presents, send greetings and letters.

The overall experience is that I have learnt myself better to know, and that is not a bad thing. My meeting with Lithuania enriched my life. 